\title{
An Authority Control Alternative for Small Colleges
}

\section{Joan M. Bechtel}

\begin{abstract}
Student and faculty need for improved access to the library's holdings is the most important, perhaps only, justifiable argument for authority control in the online public access catalog. Cost, especially in small colleges, is unavoidably a limiting factor. AutoCat authority control, developed at Dickinson College in Carlisle, Pennsylvania, enhances student ability to find and select materials. At the same time, it avoids the initial costs of vendor cleanup and LC authority tapes. Further, it significantly reduces the labor involved in creating, linking, and updating authority records.
\end{abstract}

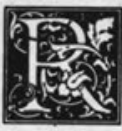

esearching a paper on apartheid in South Africa, a sophomore student in an international relations course searches the college's online catalog under the subject heading "apartheid" and discovers that the library has only two books on the subject. Another student in a literature course searches for all books by the author Hilda Doolittle and, finding none, assumes that he will have to go to another library. A third student, assigned to do a research paper on a topic of her choice in a religion course, searches under "New Testament" in the subject index and finds nothing. A fourth, working on a paper for a political science course, does a keyword search on the term "India" in the subject index and finds an overwhelming array of titles.

All four students were poorly served. The library's collections were inadequately used because the catalog had no authority control. The catalog did not tell the first student that there are many books on apartheid listed under the heading "Race relations-South Africa." Nor did the catalog bring together titles published under alternate names, automatically present them, and inform the student that Hilda Doolittle is listed under "H. D." The third student walked away empty-handed because the catalog provided no indication that, in Library of Congress subject headings, "New Testament" is indicated as "N.T." following the term "Bible." And, finally, the fourth student took down the call numbers of the first five "India" titles that came up on the screen without thinking carefully about the need to choose a more specific subtopic. Consequently, she was in danger of succumbing to the normal student temptation to write down all she had learned. The result would most likely be an amorphous, unfocused paper.

When I think about the searches encountered while assisting students in the reference area or observed while walking about the library, it is apparent that these sorts of problems occur with shocking frequency. Students at Dickinson College, in Carlisle, Pennsylvania, and I suspect elsewhere, more often than not search for materials on topics they know nothing about and treat a term paper assignment as if it were the topic of the paper they are asked to write. This misconception typically leads them

Joan M. Bechtel is a Librarian at Dickinson College, Carlisle, Pennsylvania 17013. 
either to search under simple terms that turn out to be broad topics, such as "China," "Old Testament," and "Modern Art," or that are natural language terms, such as "apartheid" and "televangelism." These simple terms may or may not have been used by the Library of Congress for a long enough period of time to encompass all relevant materials.

Keyword searching, while helping to solve the problem of user ignorance about the formation of Library of Congress subject headings, often enlarges the search results to an unmanageable level. Alternatively, keyword searching leads to false user confidence that all available materials have been found. Fully interactive with the online catalog, good authority control for subject headings and for names is imperative to solve the problems that all four of these students unwittingly encountered.

\section{Keyword searching, while helping to} solve the problem of user ignorance about the formation of Library of Congress subject headings, often enlarges the search results to an unmanageable level.

Perhaps in the past when students and faculty used the card catalog to find and choose materials, meticulous authority control was less necessary. It could be argued that librarians were almost always available to teach the use of subject headings and the intricacies of filing rules as well as to help patrons who encountered difficulties. The advent of the online public access catalog, however, means that access to the library's holdings is far more widespread. Students and faculty now commonly search the library's holdings from remote locations throughout the library, faculty offices and laboratories, classrooms, and even dormitory rooms. Furthermore, such searching is not limited to the hours when the library is open. Library catalogs are now available for searching twenty-four hours a day. The downside of this improved access is that while ter- minals are ubiquitous, tireless librarians are not. Librarians can no longer be confident that librarians are always available to assist student and faculty searching. Teaching effective use of any online catalog is necessarily a high priority for students and faculty who have not had such instruction or who have forgotten some or all of it. The stories of the four students above are merely examples of the many difficulties that patrons encounter when they use online catalogs. In fact, the ease of use and the high tech magic of the public access catalog tend either to seduce patrons into thinking that they have found all that is available on their topic or, alternatively, to frustrate enormously the timid or the more discerning patrons. Therefore, interactive authority control is imperative to enhance, rather than impede, the teaching-learning process in all institutions of higher learning.

\section{BACKGROUND}

Since at least the mid-1970s, when the development of online catalogs was widely discussed, authority control and keyword searching have been on every librarian's wish list. However, the difficulties and costs of development along with required storage space largely precluded the inclusion of either in the earliest catalogs. In the last three to five years, however, keyword searching and authority control have become widely available in one form or another. While some still argue that authority control is an expensive, expendable nicety or that keyword searching vitiates the need for it, most agree that authority control is highly desirable, if not a necessity. ${ }^{1}$

The literature is replete with articles assessing the capabilities of authority control in online catalogs, the need for it by both librarians and users, and the high cost of providing authority control. ${ }^{2,3,4}$ Aside from those like Lois Mai Chan, whose principal interest is subject access, the emphasis in the literature has been on the mechanics of providing authority control and on its use by and benefits to catalogers. Understandably, the arguments for authority control vary widely 
with the perspective of the writer or speaker. Nevertheless, in an undergraduate academic library the most persuasive and responsible argument for providing authority control is that retrieval and use of information are significantly enhanced. If the organization of materials is improved, that is, if the work of the catalog librarians is also enhanced by authority control, that is a bonus. Academic librarians, however, must not lose sight of the fact that their raison d'être is service to students and faculty, not their own comfort.

\section{THE PROBLEM}

As pointed out in the literature, and as most technical services librarians know, authority work is labor intensive and, therefore, expensive. ${ }^{5}$ Currently, the typical method for providing online authority control is the integration of the Library of Congress (LC) authority records on magnetic tape with a local online catalog. The meaning of the term integration varies widely. At the least it can mean that librarians consult the LC authority file on OCLC, or on another utility, when establishing headings, or that a vendor compares a library's bibliographic records on MARC tapes with the LC authority file on tape in order to correct invalid name and subject headings. The result is a one-time only cleanup of the headings in a library's bibliographic records. If a file of the authority records used in the cleanup is provided, they are not linked with the bibliographic records. Integration can also mean that the library purchases the LC tapes along with the online catalog and either runs the tapes against the bibliographic file to find needed headings, or a librarian manually searches the files and downloads them. ${ }^{6}$ In either case a librarian must edit the authority records for use in the local catalog. Subsequently, the authority records may or may not be linked to all the appropriate bibliographic records so that control can be maintained through global editing when changes become necessary.

Purchasing LC tapes, downloading, editing, and linking authority and biblio- graphic records, no matter how badly needed, are beyond the means of many small undergraduate colleges because the cost of the tapes is high and the labor needed to accomplish the tasks is expensive. According to Barbara B. Tillett, founder and former chairperson of the Authority Control Interest Group of the American Library Association, some libraries spend more than half their cataloging budgets on authority work. ${ }^{7}$ In 1977-78 the University of Texas at Austin spent $\$ 145,000$ on authority control. Authority control cost the libraries in the Association of Research Libraries about $\$ 5$ million in 1979 . Authority work at Yale reportedly took five to ten times longer than descriptive cataloging. ${ }^{8}$

In fact, the ease of use and the high tech magic of the public access catalog tend either to seduce patrons into thinking that they have found all that is available on their topic or, alternatively, to frustrate enormously the timid or the more discerning patrons.

Cost is not the only problem. LC authority records often are inappropriate for small colleges. Undergraduate libraries actually need only a small fraction of the authority headings on the tapes, and many of those contain large numbers of cross-references that need to be removed because they confuse users, take up storage space unnecessarily, and slow down the system. For instance, the LC authority record for William Shakespeare contains references for his name in a great many foreign languages, most of which are not needed in a small college library.

In the mid-1980s Dickinson librarians involved in developing AutoCat, the college's online catalog, knew that authority control was absolutely necessary for providing undergraduates with improved access to the library's holdings. However, those librarians also knew that both the initial costs for vendor cleanup (estimated to be $\$ 12,000$ for Dickinson in 
1984), purchase of the LC tapes when available, and the ongoing labor costs for capturing and editing new records and maintenance of the entire system would be very high. Consequently, the librarians began thinking about alternate possibilities for providing the collocating function and for providing consistency in the database.

\section{DEVELOPMENT}

The first questions, then, had to do with the function of authority control in an institution of liberal education. What do undergraduates need most, not only to improve retrieval of wanted and needed materials, but also to contribute to their ability to think carefully about the work they are doing? Two functions appeared to be of primary importance:

1. Organizing like materials into consistent, intelligible groups so that users can assess the quantity of information available in the category they choose and so that they can, in many cases, see an array of related, but different, groups of materials.

2. Automatic conversion of invalid search terms into valid ones so that the existing, needed material is immediately and clearly presented.

The downside of this improved access is that while terminals are ubiquitous, tireless librarians are not.

The issue of the exact form of name or subject heading currently in use by the Library of Congress seemed of lesser importance. In fact, the librarians concluded fairly quickly that bringing like materials together under one heading, was of primary importance. The form of that heading was clearly secondary. Students and faculty in an undergraduate institution are not concerned about the exact form of a name or subject heading. However, they do want their search terms to retrieve all relevant items. Therefore, the collocating function and the provision of cross references are the primary concerns.
Additionally, the librarians determined that authority control in an online system must provide continuous control of both new records entering the system and older records already in the database. Therefore, a cleanup of the database by an outside vendor would not do. Real control has to mean that new records coming into the system are automatically updated to correct or validate term usage and are linked to the appropriate authority records so that the new records and those already in the system are organized together. Then they can be accessed and automatically globally changed should that subsequently become necessary. Finally, all of this had to be provided as economically as possible.

\section{AUTOCAT AUTHORITY CONTROL}

AutoCat's authority control, in place since the introduction of the full system in the spring of 1987, fulfills the early requirements detailed above. Furthermore, AutoCat does so in labor-saving ways without the added expense of purchasing LC tapes. As of September 1991, the AutoCat database contained 254,503 bibliographic records, 210,521 name authority records, 169,350 subject heading authority records, and 210,521 phrase authority records for phrases in subject headings. The database has proved to be a highly satisfactory, affordable alternative to the usual authority control modules in online catalogs.

\section{Name and Subject Heading Authority Records}

During the initial load of the AutoCat database, authority records were automatically created from the bibliographic records for all names-personal, corporate, and conference-and for all subject headings. The machine-created authority records were constructed according to a table of equivalents painstakingly worked out by the librarians using the MARC formats for bibliographic records and the MARC format for authority records. The table of equivalents detailed the exact correspondence of each name and subject heading field in the MARC bibliographic formats to 
specific fields in the MARC authority records.

Bibliographic records with 87X fields containing invalid name headings were loaded first with the $87 \mathrm{X}$ fields automatically added to the name authority records as $4 \mathrm{XX}$ cross-reference fields. The remaining bibliographic records were then loaded with all name headings passing by these name authorities so that the 4XX fields served to clean up other bibliographic records that had been converted to magnetic tape before OCLC's AACR2 conversion. Because no available fields on the bibliographic records existed for invalid subject headings, minimal level subject authority records were automatically created as well. Cross references would be added later.

\section{Phrase Authority Records}

Working from printouts containing all the subject headings on the library's archive tapes, the librarians created nearly 3,000 phrase authority records in a MARC-like format. These records serve to control phrases within subject headings. The phrase authority control was a new idea at the time. The only available model for a machine-readable format was the MARC authority records' format, which was carefully followed so that these phrase authority records could be as transportable to other systems as are all the AutoCat name and subject authority records. These phrases controlling topical and geographic terms at the subfield level are single as well as multiple words and can be coded to serve as a main heading and/or a subdivision. They can also be coded for removal, as in "Addresses, essays and lectures," a subdivision that is no longer used by the Library of Congress. ${ }^{9}$ Crossreferences for all the invalid forms of these phrases represented on the tapes were included so that during the initial load, and ever after, such invalid forms are automatically corrected to the valid form. The project, initially labor-intensive, has been worth that effort because of its continuing utility. See figures 1-4 for examples of name, subject heading, and phrase authority records.
At the very beginning of AutoCat, three authority files were createdname, subject heading, and phrases in subjects. $4 \mathrm{XX}$ fields automatically created from the 87X fields corrected names during the load, and 4XX fields on the phrase authority records corrected occurrences of those phrases in subject headings. This use of the name authority records and the phrase authority records during the initial load accomplished a good deal of the cleanup of bibliographic records normally done by a vendor. Other features are normalization of capitalization and some punctuation, careful attention to preserving and facilitating the use of all diacriticals, and the MERGE facility described below. The features also assist in accomplishing cleanup of the database so that the cost of vendor manipulation is saved.

At the same time that authority records were automatically created, the bibliographic records were machine linked to all the appropriate authority records providing the global change capacity needed for continuous, efficient updating. Those three authority files continue to be available to librarians in three separate, alphabetic, online lists. All the authority records are available to librarians and patrons in the search module where they can be displayed in the full or MARC format and where librarians can edit and merge them, as described below.

The authority records and the bibliographic records they control are fully interactive. That is, authority records and bibliographic records can be edited with the assurance that all needed authority changes and linkages will automatically be made. A change to an authority record results in automatic changes to all linked bibliographic records as well as linking to a different authority record or automatic creation of a new authority record. An edit of an authority controlled field in a bibliographic record results in a relinking with the correct authority record or the creation of a new authority record. When the last bibliographic record is removed from an authority record, that authority 


\begin{tabular}{|lllll|}
\hline $\begin{array}{l}\text { Control: A2687X } \\
\text { Type: } z\end{array}$ & $\begin{array}{l}\text { Rec stat: } \\
\text { Govt Agn: I }\end{array}$ & $\begin{array}{l}\text { Entrd: 870206 } \\
\text { Lang: I I }\end{array}$ & $\begin{array}{l}\text { Used: 870206 } \\
\text { Source: }\end{array}$ \\
Enc Lvl: $n$ & & $\begin{array}{l}\text { Head sta: a } \\
\text { Name: I }\end{array}$ & $\begin{array}{l}\text { Mod red: I } \\
>040\end{array}$ \\
$>100$ & 00 & \# a & H. D. \#q (Hilda Doolittle), \#d 1886-1961 \\
$>400$ & 10 & \# a & Helforth, John \# w I dak \\
$>400$ & 10 & \# a & Doolittle, Hilda, \# d 1886-1961 \# w I dax \\
$>400$ & 10 & \# a & Aldington, Hilda (Doolittle) \# d 1886- \# w I dak \\
$>400$ & 00 & \# a & H. D. \# w I dax \\
$>400$ & 00 & \# a & H. D. \# q (Hilda Doolittle, \# d 1886-1961 \# w I dax \\
$>400$ & 10 & \# a & Aldington, Mrs. Hilda (Doolittle) \# d 1886- \# w I dax \\
\hline
\end{tabular}

\section{FIGURE 1}

Name Authority Record

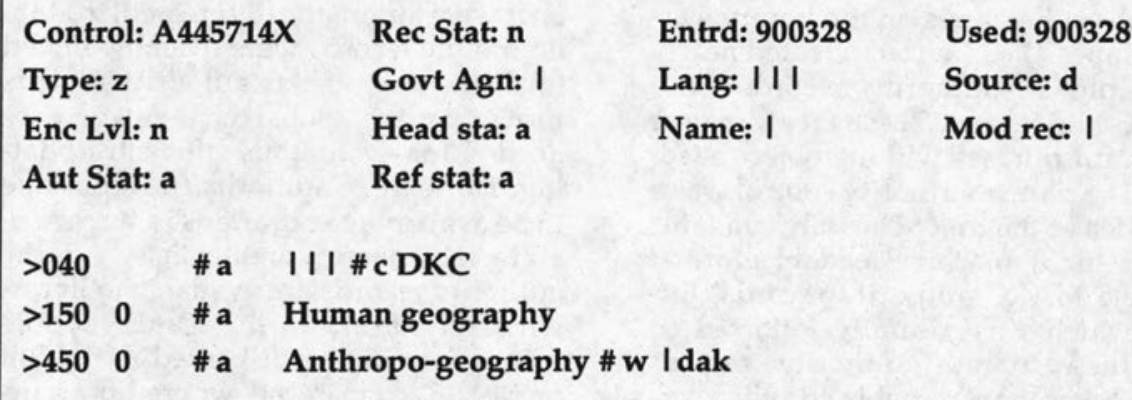

\section{FIGURE 2}

Subject Authority Record

record is deleted from the system. No empty authority records or blind references are left behind.

\section{Hierarchical Structure of Authority Records}

The hierarchical structure of authority records ensures that a name in the system always appears in the same, identical form throughout, whether it appears as an author or as a subject, and that controlled phrases in subject headings always appear in the same form. For instance, the subdivision "History and criticism" always appears in that form and never appears as "Hist. \& crit." or "History \& criticism." This feature ensures collocation of like materials. Hierarchy of structure means that the name authority record controls both the name fields in which the name appears as author and the name portion of all subject heading authority records. For example, the name authority record for "Hilda Doolittle" (figure 1) contains "H.D." as the valid form and is linked to, and therefore controls, all the author fields in the appropriate bibliographic records with the result that "H.D." appears as the author of Hilda Doolittle's 


\begin{tabular}{|c|c|c|c|c|c|}
\hline \multicolumn{3}{|c|}{ Control: A1917X } & Rec stat: n & Entrd: 870206 & Used: 870206 \\
\hline \multicolumn{3}{|c|}{ Type: z } & Govt Agn: I & Lang: I | I & Source: $\mathbf{u}$ \\
\hline \multicolumn{3}{|c|}{ Enc Lvl: $\mathbf{n}$} & Head sta: a & Name: I & Mod rec: I \\
\hline \multicolumn{3}{|c|}{ Aut stat: a } & Ref stat: a & & \\
\hline$>040$ & & $\# \mathbf{a}$ & DKC & & \\
\hline$>150$ & 00 & $\# \mathbf{a}$ & Social life a & ustoms & \\
\hline$>450$ & 0 & $\# \mathbf{a}$ & Social life 8 & oms \# w I nak & \\
\hline$>450$ & 0 & $\# \mathbf{a}$ & Soc. life \& & w I nak & \\
\hline$>450$ & 0 & $\# \mathbf{a}$ & Soc. life an & t \# w I nax & \\
\hline$>450$ & 0 & $\# \mathbf{a}$ & Social life a & stom \# w I nak & \\
\hline$>450$ & 0 & $\# \mathbf{a}$ & Social life a & onditions \# w I nak & \\
\hline$>450$ & 0 & $\# \mathbf{a}$ & Social histo & w I nak & \\
\hline
\end{tabular}

\section{FIGURE 3}

Phrase Authority Record

\begin{tabular}{|c|c|c|c|c|c|}
\hline \multicolumn{3}{|c|}{ Control: A969X } & Rec stat: $\mathbf{n}$ & Entrd: 870206 & Used: 870206 \\
\hline \multicolumn{3}{|c|}{ Type: $\mathbf{z}$} & Govt Agn: I & Lang: III & Source: $\mathbf{u}$ \\
\hline \multicolumn{3}{|c|}{ Enc Lvl: n } & Head sta: a & Name: I & Mod rec: I \\
\hline \multicolumn{3}{|c|}{ Aut Stat: a } & Ref Stat: a & & \\
\hline$>040$ & & \# a & DKC & & \\
\hline$>151$ & 00 & $\# \mathbf{a}$ & Germany (We & & \\
\hline$>451$ & 0 & $\# \mathbf{a}$ & German Fede & epublic \# w I nak & \\
\hline$>451$ & 0 & $\# \mathbf{a}$ & Germany (Fe & Republic, 1947- & w I nak \\
\hline$>451$ & 0 & $\# \mathbf{a}$ & Germany, Fed & Republic of \# w I & \\
\hline$>451$ & 0 & $\# \mathbf{a}$ & Germany, We & I nax & \\
\hline$>451$ & $\mathbf{0}$ & $\# \mathbf{a}$ & German, Wes & w I nak & \\
\hline$>451$ & 0 & $\# \mathbf{a}$ & West German & Inax & \\
\hline$>451$ & o & $\# \mathbf{a}$ & Western Gern & \# w I nax & \\
\hline$>451$ & $\mathbf{0}$ & $\# \mathbf{a}$ & $\begin{array}{l}\text { German (Terr } \\
\text { zone) \# w I n }\end{array}$ & nder Allied occu & tion, 1945-1955. U.S. \\
\hline$>451$ & 0 & $\# \mathbf{a}$ & $\begin{array}{l}\text { German (Ter } \\
\text { French zone) }\end{array}$ & $\begin{array}{l}\text { under Allied } \\
\text { lak }\end{array}$ & upation, 1945-1955. \\
\hline
\end{tabular}

FIGURE 4

Phrase Authority Record for a Geographic Entity 
works. The authority record also has several $4 \mathrm{XX}$ fields that correct incoming records and correct a patron's search term from the invalid form to "H.D." The name authority record controls the name "H.D." in all appropriate subject heading authority records, e.g. "H.D.-History and Criticism," "H.D.-Biography." Those subject heading authority records, in turn, control the linked fields in all the relevant bibliographic records. The result is that "Hilda Doolittle" always appears as "H.D." whether she is the author or the subject of a work. Consistency in the use of her name is ensured throughout the system. Because of this hierarchical system with the name authority record at the top, all merging and editing of names are done in the name authority record and not in the subject authority record where that name appears.

Similarly, phrase authority records do not control fields in bibliographic records. Rather, they control portions of subject authority records that contain the phrase. The subject authority records containing the phrase in a particular subfield, in turn, control all the related bibliographic records. Editing of phrases, therefore, may only occur in the phrase authority record, thereby ensuring consistency and enabling, with a single edit, updating of appropriate subject headings throughout the entire database. For a chart that depicts the hierarchical relationships of authority records, see figures 5 and 6.

\section{Merging and Editing Authority Records}

Full merging and editing of name authority records and subject authority records have been available to Dickinson librarians for more than two years. ${ }^{10}$ The MERGE function, a new idea generated at Dickinson, facilitates efficient correction of names and subject headings by allowing the librarians to merge with one command an invalid heading into a valid one and, if desired, to retain the invalid form as a $4 \mathrm{XX}$ cross-reference or see reference on the valid authority record." The result of a single MERGE command, with the request to retain the invalid form, is that:
1. The two authority records are merged into one with the invalid term retained as a $4 \mathrm{XX}$ see reference.

2. All bibliographic records attached to the invalid form are automatically corrected.

3. All bibliographic records are automatically linked to the valid heading.

4. All bibliographic records coming into the database with the invalid term that now appears in a $4 \mathrm{XX}$ field are automatically corrected and linked to this valid authority record.

5. User searches employing the invalid terms in the $4 X X$ field automatically retrieve the records attached to the valid term.

Because the MERGE facility is available to authorized librarians within the search module, merges can be performed quickly and easily as the librarians are using the database for other purposes, such as routine searching, cataloging or creating bibliographies. Of course cleanup projects are designed and carried out when student help is available, but cleanup need not wait for the initiation of such a project. For example, a librarian, perhaps preparing a bibliography for class instruction, discovers that a name that is important for that class has several forms. The librarian can immediately merge the various forms into the single correct one. (Multiple merges into one valid authority record can be queued so that they are performed in order.) The merges will take place that night in batch mode so that the newly corrected form of the name authority and related bibliographic records will all be available to the class in the morning. Another librarian cataloging a new book may discover that the subject heading for this book has undergone a change, that related items already in the collection have an old form of the subject heading, and that another related book in the collection has a misspelling in the subject heading. These problems can be quickly corrected using the MERGE facility and invalid forms retained as cross references, if the librarian deems it necessary (see figure 7). 


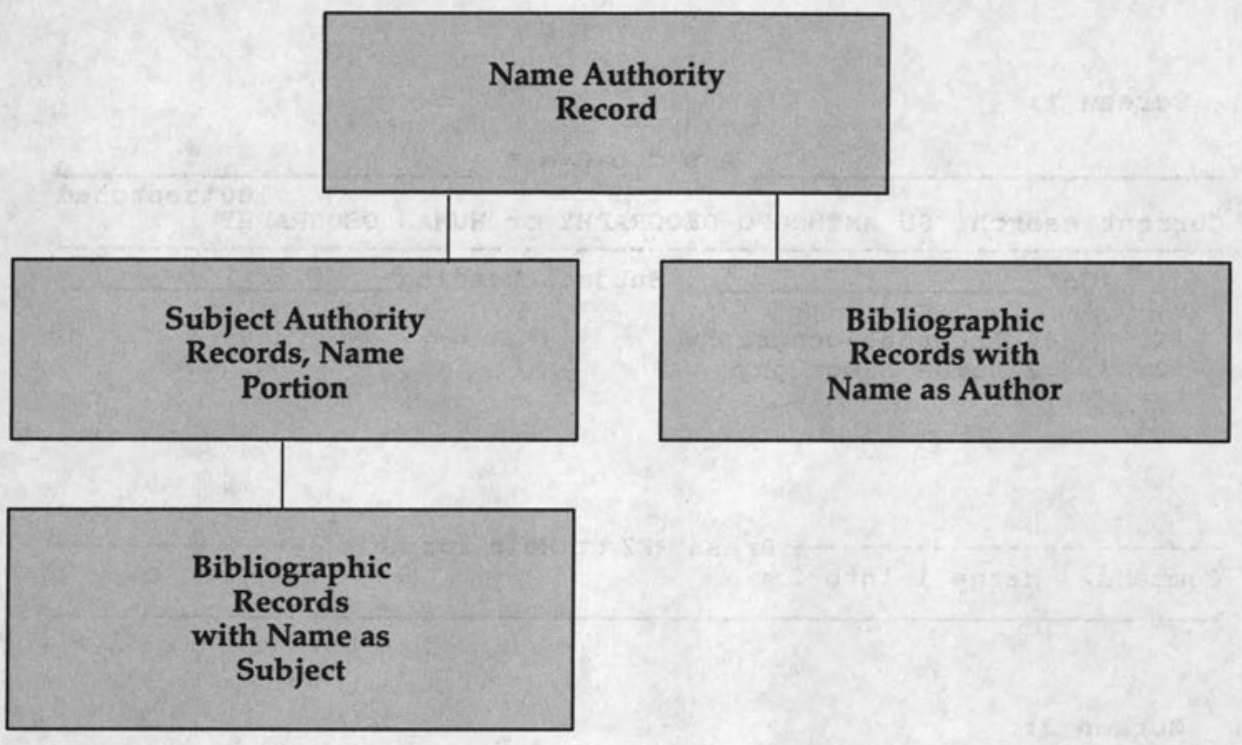

FIGURE 5

Relationship of Name Authority Records to Subject Authority Records and to Bibliographic Records

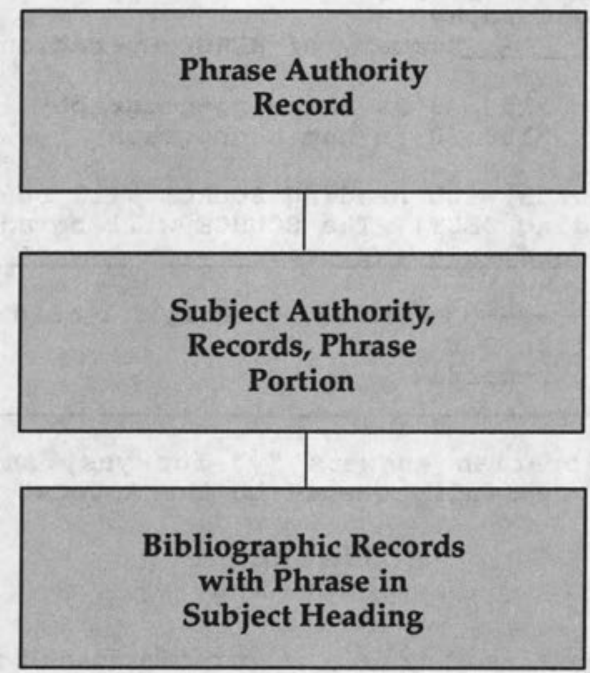

FIGURE 6

Relationship of Phrase Authority Records to Subject Authority Records and to Bibliographic Records 
Screen 1:

A a $t$ o c a $t$

$100 \%$ searched

Current search: SU ANTHROPO-GEOGRAPHY Or HUMAN GEOGRAPHY

Cnt Subject Heading

1. 44 Anthropo-geography

2. 2 Human geography

Command> Merge 1 into $2 r$

Press PF2 or Help for help

C

Screen 2:

Current search: SU ANTHROPO-GEOGRAPHY Or HUMAN GEOGRAPHY

100searched

Cnt_ Subject Heading

1. 44 Anthropo-geography

2. 2 Human geography

Summary of MERGE Operation

\begin{tabular}{l}
\hline Summary of MERGE Operation__ \\
Source: $>150$ o Anthropo-geography \\
Dest: $>150$ a Human geography \\
All records with heading SOURCE will be changed to \\
use heading DEST. The SOURCE will be added to the \\
DEST record as a $4 \times x$ tag.
\end{tabular}

Command> Merge 1 into $2 r$

Press PF2 or Help for help

Really merge those records?

When the librarian answers " $y$ " for yes, Autocat responds, "Merge request successfully queued to the Autocat Daemon."

\section{FIGURE 7}

MERGE Facility

As mentioned above, editing of authority records and bibliographic records is fully interactive both in field coding and content as well as in the linking of authority and bibliographic records. Full editing of authority records also means that $4 \mathrm{XX}$ see references can be added to authority records according to the needs of students and faculty of a particular institution. Alternate spellings, for example, are easily added. Each time I search for Dostoyevskii and come up with no hits, I add the particular spelling that failed to the list of 400 fields on the name authority record so that a student who spells Russian as poorly as I do will be sure to find all the books by and about this important Russian author. In thesame way, 
A a $t$ o c a $t$

Current search: SU KING ARTHUR

100 ssearched

Cnt

subject Heading

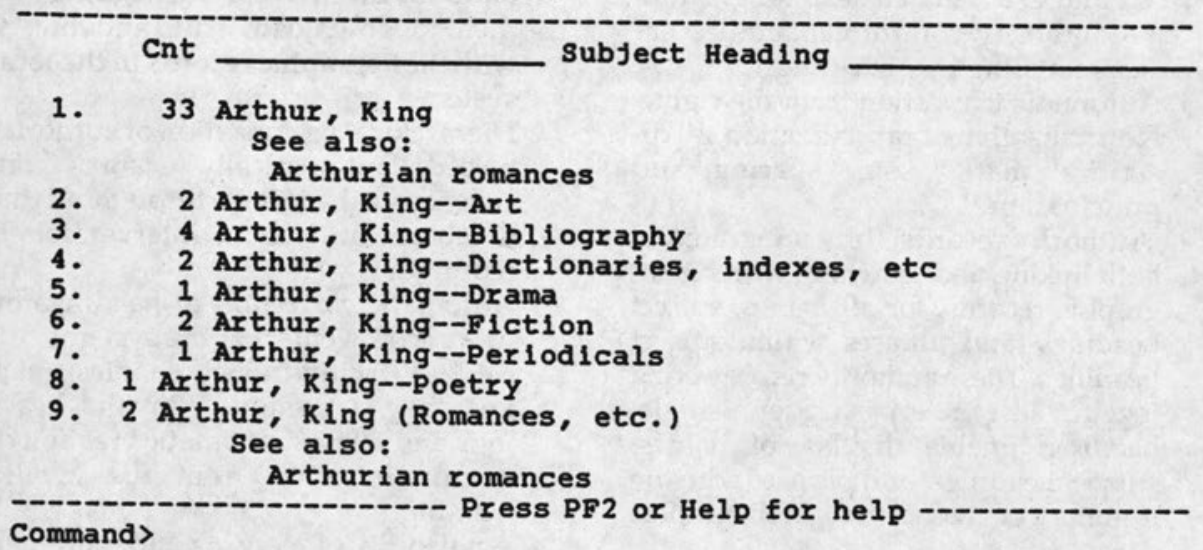

FIGURE 8

Display of See Also References

needed 5XX "see also" references (as well as $6 \mathrm{XX}$, source and scope notes) can be added. Knowing about related subject headings is particularly important for undergraduate subject searching and is, therefore, a high priority for the future. Although, the librarians have been adding them "on the fly," we have given high priority to designing a student project for systematically adding a large number of "see also" references (see figure 8).

\section{PRACTICE}

Because all nine librarians at Dickinson have cataloging responsibilities, all undergo training in the use of OCLC for technical services, in authority work, and in editing AutoCat bibliographic and authority records. When they reach the required level of proficiency, they are given the authority-edit and authoritymerge privileges so that all can contribute to the improvement of authority control in the database.

Quality control is maintained in training and revision procedures. Additionally, AutoCat provides a weekly report that lists all the changes in the database affecting authority control. A designated librarian quickly reviews the week's authority work to identify any problems. If a problem that warrants retraining or discussion occurs, an audit facility in AutoCat can identify who did the work and when.

Anglo-American Cataloguing Rules 2 (AACR2) and LC interpretations of it do provide the standard for authority work. Routine practice is to search the OCLC online authority file for establishing a name when it is new to the database or when a conflict occurs in AutoCat. The current LC form is the standard normally used as the valid form in AutoCat. However, if LC has no authority record in AACR2 form on OCLC, the librarians establish the name according to AACR2, to the best of their ability, and, using either MERGE or EDIT, add the necessary cross references. The librarians do not spend a great deal of time searching for or agonizing over the exact, correct form because the structure and functioning of AutoCat vitiate the need to make a meticulous distinction between the correct and incorrect forms of a particular heading. ${ }^{12}$

\section{SUMMARY}

AutoCat provides for small colleges a viable alternative approach to authority control because it effectively enhances user ability to find needed material in 
the college's collection, and it does it economically. Fully integrated with keyword and exact match searching, AutoCat's authority control capabilities enhance searching by providing:

- Automatic truncation from the right.

- Normalization of capitalization, all diacritical marks, some spacing, and punctuation. ${ }^{13}$

- Authority records, fully integrated in both linking and searching with bibliographic records, for all names, subject headings, and phrases within subject headings. These authority records bring together like materials under a single, heading; enable display of names, subject headings, and phrases with the number of associated bibliographic

AutoCat provides for small colleges a viable alternative approach to authority control because it effectively enhances user ability to find needed material in the college's collection and it does it economically.

items so that the user can make an informed choice; provide consistency in term usage; automatically correct invalid search terms to the correct form; and suggest related search terms.

- Editing and merging of authority records so that authority records are kept up to date.

- Automatic correction and linking of new bibliographic records coming into the system.

AutoCat's authority control reduces costs in two ways. First, a library's machine-readable bibliographic records do not need to go to an outside vendor for a one-time only cleanup. Purchasing the LC authority file on magnetic tape is also not required. Secondly, human labor costs are significantly reduced by:

- Automatic use, during the initial load of the database, of the 870 fields to provide cross-references for names that OCLC corrected in its AACR2 "flip."

- Automatic creation of minimal level authority records from the biblio- graphic records. (This process saves the human labor required to search LC tapes for the appropriate heading and then to download, edit, and link it with bibliographic records in the local system.)

- Hierarchical organization of authority records automatically ensures consistency of headings throughout the database; no human intervention is required.

- Automatic correction of headings on new records entering the system.

- MERGE facility which enables quick and easy correction of invalid headings and allows automatic creation of a cross-reference from the invalid heading.

- Availability of merging and editing to authorized users within the search module so that librarians can perform authority work to improve the database while they are using AutoCat for other purposes.

- Identical editing for authority and bibliographic records so there is no need for additional training. ${ }^{14}$

- Automatic verification of fields and subfields for editing and merging of authority records. An edited or merged record determined to be incorrect is returned to the user with a 999 field indicating the error.

\section{CONCLUSION}

The information needs of students and faculty in the era of widely dispersed, independent access afforded by online catalogs demand that librarians provide authority control for all names and subjects in the public catalog. AutoCat authority control significantly enhances users' ability to find and evaluate the materials they need. For example, in AutoCat the searches for works written by Hilda Doolittle and for materials about apartheid and the New Testament encounter cross-references that lead to all the relevant information in the collection. The student searching on the term "India," rather than facing screen after screen of unsorted titles, sees a list of subject headings derived from the subject authority file and containing the 
term "India" with the number of items attached to each heading. This list enables the student to begin to think about possible subtopics that are of a more manageable size and that might be of interest. Choosing a smaller topic from the list of subject headings and retrieving only the related materials, the student is enabled to write a tightly argued, more focused paper.

AutoCat provides economically viable authority control capabilities by reducing payments to outside agencies and by markedly reducing human labor. The twin goals of providing information retrieval that embodies the needed finding and sorting functions and of doing so as economically as possible do not, however, require slavish dependence upon the LC authority file. While AutoCat itself may never be on the market, its unique approach to authority control provides a new model for use in small colleges where the curriculum and size of the collection do not warrant using the LC authority files. Further, AutoCat's phrase authority control points the way to far more efficient subject authority control because it provides the means to accomplish consistency of usage and global change without laboriously correcting a single phrase each time it occurs in a subject heading. And finally, the notion of a MERGE facility enables accurate and efficient collocation of materials, updating of authority records and the addition of cross references all at the same time.

Small college librarians, many of whom have not yet purchased an online catalog, can have a significant effect on what is available by insisting that vendors provide effective, affordable authority control. An AutoCat or AutoCat-like approach to authority control permits, even encourages, adopting the principle that authority control, any authority control, is better than no control. It prevents perfection from becoming the enemy of the good. The focus is on improving faculty and student location and choice of material, so critical to the teaching-learning process, rather than upon unwavering adherence to national and international standards. AutoCat, or yet to be developed systems like it, economically incorporates the tools necessary to provide excellent authority controlled organization of the database and facilitates searching in ways that help students not only to find the materials they need but also to choose wisely from the seemingly chaotic complexities of information contained in the college library.

\section{REFERENCES AND NOTES}

1. See Tamara S. Weintraub, "Personal Name Variations: Implications for Authority Control in Computerized Catalogs," Library Resources \& Technical Services 35:217-28 (Apr. 1991) in which she states, "In an online system many personal name authority records thus seem to be, as others have suggested, a duplication of information that contributes little more to the success of a personal name search query of the catalog than data in bibliographic records," p.224.

2. See Robert H. Burger, Authority Work: The Creation, Use, Maintenance, and Evaluation of Authority Records and Files (Littleton, Colo.: Libraries Unlimited, 1985): Sarah Hager Johnson, "Current Offerings in Automated Authority Control: A Survey of Vendors," Information Technology and Libraries 8:236-64 (Sept. 1989); Doris Hargrett Clack, Authority Control: Principles, Applications and Instructions (Chicago and London: American Library Assn., 1990); and articles by Roberta F. Kirby, Helen Goodman, David M. Smith, Michael Ridgeway, George E. Gibbs, and Diane Bisom in Authority Control in the Online Environment: Considerations and Practices (New York and London: Haworth, 1989).

3. See, for instance, Ann M. Fiegen, Sara C. Heitshu, and Edward P. Miller, "The Effect of the LASS Microcomputer Software on the Cost of Authority Work in Cataloging," Information Technology and Libraries 9:253-57 (Sept. 1990); Lois Mai Chan, "Subject Analysis Tools Online: The Challenge Ahead," Information Technology and Libraries 9:258-62 (Sept. 1990; Noelle Van Pulis and Lorene E. Ludy, "Subject Searching an Online Catalog with Authority Control," College \& Research Libraries 49:523-33 (Nov. 
1988); Fumiko H. Coyne and Ingrid Mifflin, "Shared Authority Control at the Western Library Network," Library Resources \& Technical Services 34:493-503 (Oct. 1990).

4. See especially Fiegen, Heitshu and Miller, "The Effect of the LASS Microcomputer," p.253-57.

5. Authority control and authority work mean two different things. Authority control is the overall term for providing consistency in headings and for bringing together under those headings all the appropriate materials. Authority work is the intellectual effort and research work involved in creating and maintaining authority records.

6. The Library of Congress authority file is available on microfiche as well as on magnetic tape. For a long time, many academic libraries have subscribed to the microfiche version or have received it as a depository item. Some libraries with online catalogs may continue to use the fiche version of the LC authority file for establishing headings.

7. Barbara B. Tillett, ed., Authority Control in the Online Environment: Considerations and Practices (New York and London: Haworth, 1989), p.7.

8. Arlene G. Taylor, "Research and Theoretical Considerations in Authority Control," Authority Control in the Online Environment: Considerations and Practices, Barbara B. Tillett, ed. (New York and London, Haworth, 1989) p.33.

9. The values and related meanings for the first indicator position on valid phrases in subject headings are:

9-Delete this phrase from all subject headings, whether the phrase is the main or subordinate divisions.

8-This phrase is valid if it appears in the main division only.

7-This phrase is valid if it appears in subordinate divisions only.

0 -This phrase is valid whether it appears in the main or subordinate divisions.

10. Editing and merging of phrases are currently in development and are expected to have the same capabilities as names and subjects.

11. In order to save storage space, the librarian can choose to index the terms in a particular 4XX field using the last position in subfield $\mathrm{w}$. Two values for that position are described: $k=$ index the terms in this field, $x=$ do not index the terms in this field. If the terms already appear in the authority record, perhaps in a different order, there is no need to index; the existing terms provide access. The field is necessary, however, to correct incoming records, to link them with this authority record, and to provide exact match access. This use of subfield $w$ takes full advantage of the search capabilities of keyword searching and, at the same time, avoids space-consuming redundancy. For a discussion of studies that suggest that cataloging rules need to be revised in order to eliminate redundant cross-references when keyword searching is provided in the online catalog, see Arnold S. Wajenberg, "Authority Work, Authority Records, and Authority Files," in Michael Gorman and associates, Technical Services Today and Tomorrow (Littleton, Colo.: Libraries Unlimited, 1990) p.90.

12. Michael Gorman confirms this approach when he states, "It [the authority record], in effect, abolishes the distinction between an access point and a reference. To take an example, if either "WHO" or "World Health Organization" will get the system user to relevant bibliographic records with equal speed, what does it matter which is the access point and which the reference?" Michael Gorman, "Descriptive Cataloguing: Its Past, Present, and Future," in Michael Gorman and associates, Technical Services Today and Tomorrow (Littleton, Colo.: Libraries Unlimited, 1990), p.70.

13. These functions are considered as appropriate to authority control because they assist in controlling search terms. See Tillett, Authority Control in the Online Environment, p.4.

14. AutoCat, running on a VAX 8600 machine, uses the EDT editor for full-screen editing of both authority and bibliographic records. 